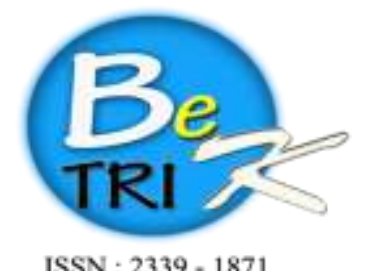

ISSN : $2339-1871$

\section{JURNAL ILMIAHBETRIK \\ Besemah Teknologi Informasi dan Komputer}

Editor Office : LPPM Sekolah Tinggi Teknologi Pagar Alam, Jn. Masik Siagim No. 75

Simpang Mbacang, Pagar Alam, SUM-SEL, Indonesia

Phone : $+62852-7901-1390$.

Email : betrik@sttpagaralam.ac.id | admin.jurnal@sttpagaralam.ac.id

Website : https:/lejournal.strpagaralam ac id/index.php/betrik/index

\title{
Pengembangan Media Pembelajaran Interaktif Jaringan Komputer Materi Intranet
}

\author{
Suherman ${ }^{1}$, Yadi $^{2}$ \\ Universitas Pembangunan Panca Budi Medan ${ }^{1}$ \\ Program Studi Teknik Informatika Sekolah Tinggi Teknologi Pagar Alam ${ }^{2}$ \\ JalanMasik Siagim No.75 Simpang Mbacang Kec.Dempo Tengah Kota Pagar Alam \\ Sur-el : suherman7749@gmail.com ${ }^{1}$, yadimkom@gmail.com ${ }^{2}$
}

\begin{abstract}
Abstrak: Teknologi yang semakin berkembang telah masuk kedalam dunia pendidikan sehingga memberikan warna yang positif bagi dunia pendidikan dengan pengembangan teknologi dan media menjadikan interaksi dalam proses pembelajaran semakin aktif dalam hal ini penelitian yang dilakukan bertujuan untuk mendukung proses pembelajaran dalam melakukan 1) perancangan media pembelajaran jaringan komputer dengan materi intranet, 2) dapat mengimplementasikan media pembelajaran jaringan komputer, 3) mengukur tingkat kelayakan media pembelajaran pada materi intranet, dengan metode research and development yang dapat di pergunakan dalam melakukan pengembangan media. Hasil penelitian menunjukkan bahwa: (1) media pembelajaran interaktif pada mata pelajaran komputer dan jaringan dasar dapat menjadi variasi media untuk pembelajaran, (2) media pembelajaran interaktif pada mata pelajaran komputer dan jaringan dasar terdiri dari materi perakitan dan perawatan komputer, video animasi perakitan komputer, video perakitan dan perawatan komputer, dan kuis pilihan ganda terdiri dari kuis perakitan komputer dan perawatan komputer dapat digunakan untuk belajar secara mandiri maupun bersama guru, (3) tingkat kelayakan media pembelajaran ditinjau dari: (a) aspek media dinyatakan "Sangat Layak" ahli media sebesar 96,52\%; (b) uji aspek materi dinyatakan "Sangat Layak" dengan hasil persentase sebesar 86,38\%; (c) penilaian pengguna atau siswa memperoleh persentase pengguna sebesar $86,42 \%$ dengan kategori "Sangat Layak".

Kunci Utama: Media Pembelajaran, Interaktif, jaringan komputer, Intranet.
\end{abstract}

Abstract : Abstract: Growing technology has entered the world of education so as to provide a positive color for the world of education with the development of technology and media making interaction in the learning process more active in this case the research conducted aims to support the learning process in doing 1) designing network learning media computers with intranet material, 2) can implement computer network learning media, 3) measure the feasibility of learning media on intranet material, with research and development methods that can be used in conducting media development. The results showed that: (1) interactive learning media on computer subjects and basic networks can be a variety of media for learning, (2) interactive learning media on computer subjects and basic networks consisting of computer assembly and maintenance materials, video animation computer assembly, video assembly and computer maintenance, and multiple choice quizzes consisting of computer assembly and computer maintenance quizzes can be used to study independently or with the teacher, (3) the feasibility level of learning media in terms of: (a) aspects of the media declared "Very Eligible" experts media by 96.52\%; (b) the material aspect test is declared "Very Eligible" with a percentage of $86.38 \%$; (c) user or student ratings get a percentage of users of $86.42 \%$ with the category "Very Eligible".

Keywords : Learning Media, Interactive, computer networks, Intranet. 


\section{PENDAHULUAN}

Pesatnya perkembangan teknologi komputer telah membawa perubahan signifikan di dunia pendidikan untuk memanfaatkan teknologi dalam proses pembelajaran, untuk meningkatkan daya saing dan keunggulan kompetitif dari sektor pendidikan, menuntut bahwa guru memiliki keterampilan kualitas yang lebih baik di bidang teknologi dan penggunaan komputer. Kegiatan belajar mengajar yang dilakukan di kelas adalah bentuk interaksi belajar antara siswa, pendidik dan sumber belajar. Pendidikan dapat dirumuskan sebagai panduan untuk menambah pengetahuan tentang salah satu proses pembelajaran yang dapat dilakukan di sekolah dengan interaksi pendidik dan siswa dalam meningkatkan soft skill dan keterampilan serta penguasaan kecakapan dalam teknologi dan pengetahuan. Dengan kata lain, belajar adalah proses untuk membantu siswa belajar dengan baik dan dapat berpikir lebih kritis. Salah satu bentuk dukungan untuk pengembangan pengetahuan siswa adalah dengan memanfaatkan fasilitas yang ada, yaitu komputer sebagai produk sains dan teknologi, dalam mendukung pembelajaran (Wati, 2016), (Sadiman, 2014).

Sekolah Teknologi Pagaralam, dalam proses pembelajaran sudah menggunakan peralatan teknologi seperti adanya infocus di ruang pembelajaran. Salah satu subjek yang menggunakan media pembelajaran adalah subyek jaringan komputer, tetapi media tersebut masih merupakan media presentasi power point biasa, terlalu sederhana dan kurang interaktif. Media pembelajaran belum dilengkapi dengan tampilan yang menarik sehingga dapat meningkatkan siswa untuk mengikuti proses pembelajaran didalam kelas. Dalam standar kompetensi jaringan kerja komputer dalam jaringan intranet sub-bahan, belum ada media pembelajaran yang dapat membantu menjelaskan pengenalan skema jaringan, sehingga menyulitkan siswa untuk memahami materi tanpa deskripsi apa pun melalui ilustrasi. Media pembelajaran yang kurang interaktif disertai dengan penyampaian materi yang kurang menarik membuat siswa merasa bosan saat mengikuti proses pembelajaran. oleh karena itu, media pembelajaran interaktif dapat menjadi alternatif yang tepat untuk mengatasi masalah ini. Media ini dibuat menggunakan perangkat lunak Macromedia Flash (Mulyatiningsih, 2013), (Munir, 2015). Tujuan dari penelitian ini adalah untuk merancang dan membuat media pembelajaran interaktif sebagai alat pembelajaran untuk Jaringan Komputer yang dikembangkan menggunakan Macromedia Flash, dalam pengembangan pembelajaran interaktif media untuk jaringan komputer.

\section{METODE PENELITIAN}

Pengembangan ini menggunakan metode pengembangan Research and Development (R\&D). (Sugiyono , 2008) Research and development salah satu metode yang dapat dipergunakan dalam penelitian untuk memperoleh produk dan menguji validasi, efektifitas produk. Tujuan dari model R\&D yaitu untuk menghasilkan produk yang empiris dan telah teruji (Endang, 2011). Penelitian ini mengambil model dari Hannafin dan Peck Karena menurut peneliti model ini berorientasi produk pembelajaran. Selain itu model ini merupakan model desain pembelajaran yang penyajiannya dilakukan secara sederhana namun elegan sehingga tidak memerlukan waktu lama (Tegeh ,2014).

1.Analisis Kebutuhan melalui tahap ini dapat di ketahui dalam pengembangan produk yang cocok di pergunakan pada proses pembelajaran, dalam mendesain produk yang dapat mendukung proses pembelajaran sesuai dengan kebutuhan. Sesudah melakukan analisis kebutuhan ini, maka selanjutnya peilaian atau evaluasi produk yang dikembangkan dilakukan untuk mengetahui apakah produk telah sesuai dengan kecakapan peserta didik sebelum ke proses yang ke dua yaitu desain.

2.Tahap desain yang selanjutnya di lakukan setelah melakukan analisa kebutuhan pada objek beserta data kebutuhan yang telah di dapat melalui proses analisa kebutuhan. proses desain ini didapat dari informasi pada tahap analisis kebutuhan dimasukan ke dalam format dokumen untuk dijadikan pembuatan desain media pembelajaran yang interaktif. Proses desain dilakukan untuk mengetahui target dan mendokumentasi agar dapat menjadi petunjuk untuk pembuatan media pembelajaran yang interktif yang sesui harapan. Format yang dihasilkan dari proses desain ini adalah dokumentasi storyboard. Storyboard dibuat untuk memperoleh keperluan yang dibutuhkan oleh siswa dalam pembuatan media pembelajaran yang interaktif. Sesudah melakukan desain, maka selanjutnya mengevaluasi dan revisi sebelum melakukan ke 
proses yang ketiga yaitu pengembangan dan implementasi.

3.Pengembangan dan Implementasi Tahap terakhir adalah tahap pengembangan dan implementasi. Tahap terakhir dalam penelitian ini, Menghasilkan diagram alur, melakukan pengujian, melakukan penilaian formatif (penilaian selama pengembangan terjadi) dan sumatif (dilakukan setelah media selesai dibuat). Sebagai landasan untuk pembuatan diagram alur yaitu dari dokumen storyboard serta membantu proses penciptaan media pembelajaran. Penilaian pada proses ini digunakan untuk menilai lancarnya media yang dihasilkan, kemudian penyesuaian dilakukan berdasarkan hasil pengujian yang diperoleh guna mencapai kualitas media.

\subsection{Media Pembelajaran Interaktif}

Model pembelajaran interaktif merupakan suatu teknik pembelajaran yang digunakan oleh guru atau fasilitator pada saat proses pembelajaran dimana guru pemeran utama dalam menciptakan situasi interaktif yang edukatif, yakni interaksi antara guru dengan siswa, siswa dengan siswa dan dengan sumber pembelajaran dalam menunjang tercapainya tujuan belajar (Dimiyati, 2014), Multimedia interaktif adalah penggunaan media yang dilengkapi dengan peralatan untuk mengontrol agar pengguna dapat mengoperasikan media yang dipilih sesuai dikehendaki untuk menjalan proses selanjutnya (Daryanto, 2013). Media pembelajaran interaktif adalah suatu sistem penyampaian pengajaran yang menyajikan materi video rekaman dengan pengendalian komputer kepada penonton (siswa) yang tidak hanya mendengar dan melihat video dan suara, tetapi juga memberikan respon yang aktif, dan respon itu yang menentukan kecepatan dan sekuensi penyajian (Azhar Arsyad, 2006). Media berupa teks, visual, dan simulasi dalam media pembelajaran interaktif bisa membantu siswa untuk mendapatkan pengetahuan, pemahaman konsep serta aplikasi yang dipelajari lebih mendalam (Suyitno, 2016), (Sadiman, 2014), (Pujiriyanto, 2012). Suatu sistem yang menampilkan pembelajaran yang berupa rekaman seperti visual, suara, dan video serta dapat dikontrol ketika disajikan melalui komputer (Pujiriyanto 2012)
Sebuah proses atau rangkaian yang dilakukan untuk menghasilkan suatu produk seperti media pembelajaran berdasarkan data yang telah didapat sehingga dapat melakukan pengembangan terhadap media pembelajaran. (Hujair AH. Sanaky, 2009), (Sudjana ,2009), (Munadi, 2018) (Daryanto, 2013), beberapa kriteria yang dapat dijadikan pertimbangan dalam melakukan pemilihan media pembelajaran yang dapat dipergunakan didalam kelas diantaranya harus memperhatikan beberapa hal a) media pembelajaran di pilih berdasarkan tujuan dan ketepatan media pembelajaran dalam menyampaikan materi yang telah di tetapkan, b) mendukung materi pelajaran dimana bahan pelajaran dapat berisi fakta, prinsip, teori dan konsep yang dapat mempergunakan media agar siswa dapat memahami dengan baik, c) media yang dipergunakan mudah untuk di dapatkan atau di desain oleh guru pada saat proses pembelajaran berlangsung d) kemampuan guru dalam menggunakan media, apapun jenis media yang diperlukan syarat utama adalah guru dapat mempergunakannya dalam proses pengajaran; (e) tersedianya waktu untuk menggunakannya, sehingga media tersebut dapat bermanfaat bagi siswa selama pengajaran berlangsung; (f) media harus mampu di pahami oleh siswa sehingga siswa dapat berfikir dengan baik dalam memahami materi melalui media pembelajaran.

\subsection{Model Penelitian Pengembangan}

Model pengembangan merupakan proses desain konseptual dalam upaya mengembangkan model yang telah ada sebelumnya dengan melakukan peningkatan fungsi beserta penambahan komponen pembelajaran yang dianggap dapat meningkatkan kualitas pencapaian tujuan pembelajaran (Sugiarta, 2007) (Daryanto, 2013). Model penelitian dan pengembangan (research and development). Model yang dipergunakan dalam pengembangan media interaktif menggunakan model ADDIE, Model ini memiliki 5 tahapan, yaitu: 1) analisis, 2) perancangan, 3) pengembangan, 4) implementasi, 5) evaluasi.

\subsection{Pengembangan Media Pembelajaran}




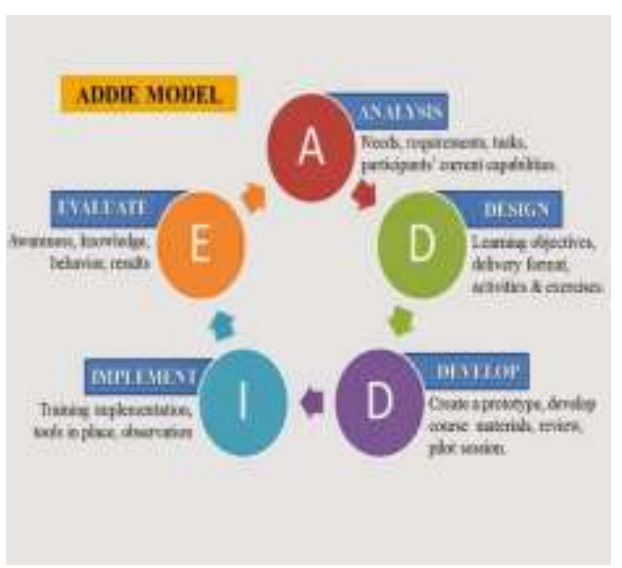

Gambar 1. Model ADDIE

\subsection{Intranet}

Intranet adalah sebuah jaringan privat (private network) yang menggunakan protokolprotokol Internet (TCP/IP), untuk memberikan informasi yang bersifat privat didalam perusahan melalui jaringan yang telah di bangun oleh perusahaan tersebut dapat melalui situs web internal perusahaan. Untuk membangun sebuah intranet, maka sebuah jaringan haruslah memiliki beberapa komponen yang membangun Internet, yakni beberapa peralatan yang dapat dipergunakan dalam membuat topologi jaringan intranet di antarnay perangkat sever dan clien berserta beberapa protocol yang bekerja pada sistem seperti adanya TCP/IP, alamat IP dan lainnya (FTP, POP3, atau SMTP) yang telah di konfigurasi agar dapat berjalan sesuai dengan tujuan, beberapa umumnya merupakan komponen protokol yang sering digunakan. Intranet mulai diperkenalkan pada tahun 1995 oleh beberapa penjual produk jaringan yang mengacu kepada kebutuhan informasi dalam bentuk web di dalam perusahaan. Intranet merupakan jaringan komputer dalam perusahaan yang menggunakan komunikasi data standar seperti dalam internet. Artinya, semua fasilitas intranet dapat digunakan untuk kebutuhan dalam suatu organisasi atau komunitas. Saat ini perangkat elektronik pintar sudah merambah di seluruh aspek kehidupan contohnya di kantor, sekolah, rumah. Beberapa sekolah sudah menerapkan teknologi intranet. Seluruh komputer terhubung dengan satu jaringan lokal. Intranet sebagai pendatang baru mengandalkan biaya yang murah, fleksibilitas, open standard, dan banyaknya vendor yang bergabung dalam menigkatkan kemampuan intranet serta jaminan perkembangan teknologi yang makin meningkat kemampuannya

\subsection{Teknik Analisis Data}

Teknik analisis data yang di pergunakan adalah analisis deskriptif penelitian ini dilakukan untuk menguji tingkat kelayakan media pembelajaran dengan menggunakan skala linkert (Sanaky, 2009) dalam pengembangan instrument dalam mengukur media dengan skor range 1) Sangat tidak setuju, 2) Tidak setuju, 3) ragu ragu, 4) Setuju, 5) Sangat Setuju. Analisa yang dilakukan berupa data kuantitatif. Untuk dapat mengetahui bahwa pengembangan yang dilakukan layak atau tidaknya dapat mengacu pada pemdoman kriteria tingkat kelayakan berdasarkan simpangan baku ideal, (Widoyoko, 2017), (Arsyad, 2014).

Tabel 1. Pedoman Kriteria Tingkat Kelayakan

\begin{tabular}{|c|c|}
\hline Rumus & Kategori \\
\hline $\begin{array}{c}\text { Skor minimal } \leq \mathrm{X} \\
\leq \mathrm{Xi}-1,8 \mathrm{Sbi}\end{array}$ & Tidak Layak \\
\hline Skor minimal $\leq \mathrm{X}$ & Kurang Layak \\
$\leq \mathrm{Xi}-1,8 \mathrm{Sbi}$ & \\
\hline $\mathrm{xi}-0,6 \mathrm{SBi}<\mathrm{X} \leq$ & Cukup Layak \\
$\mathrm{Xi}+0,6 \mathrm{Sbi}$ & \\
\hline $\mathrm{xi}+0,6 \mathrm{SBi}<\mathrm{X} \leq$ & Layak \\
$\mathrm{Xi}+1,8 \mathrm{Sbi}$ & \\
\hline $\begin{array}{c}\text { Skor max } \geq \mathrm{X}>\mathrm{Xi} \\
+1,8 \mathrm{Sbi}\end{array}$ & Sangat Layak \\
\hline
\end{tabular}

Keterangan dimana:

$\mathrm{X}=$ skor aktual rata - rata

$\mathrm{Xi}=$ ideal 41 nilai rata - rata

$\mathrm{Xi}=\mathbf{1} / \mathbf{2}$ (skor tertinggi + skor terendah)

$\mathrm{SBi}=$ Simpangan Baku ideal

$\mathrm{SBi}=\mathbf{1 / 6}$ (skor tertinggi-skor terendah)

\section{HASIL DAN PEMBAHASAN}

Model dalam penelitian ini menggunakan model Hannafin dan Peck dengan pengembangan tiga langkah, yaitu: 1) analisis kebutuhan, 2) desain produk, 3) pengembangan dan implementasi. Tujuan dalam tahapan tersebut di pergunakan dalam melakukan pengembangan media pembelajaran pada mata pelajaran komputer dan jaringan dengan materi intranet (Sudjana, 2009).

Dalam melakukan uji validasi tes dilakukan dengan menyebarkan beberaka angket kepada mahasiswa dan pakar untuk mendapatkan kritik, saran serta pendapat dalam pengembangan 
median interaktif hasil tes yang dilakukan pada materi seperti pada tabel 2.

\section{Tabel 2. Uji Materi}

\begin{tabular}{lc}
\hline \multicolumn{1}{c}{ Aspek } & Nilai \\
\hline Kualitas isi & 79 \\
\hline Kemanfaatan & 16 \\
\hline Total & 95 \\
\hline Presentase & 86.36 \\
\hline Kategori & Sangat Layak \\
\hline
\end{tabular}

Pada pengujian ahli materi tabel 1 terlihat persentase sebesar 86.36 dengan kategori sangat layak materi sesuai dengan konsep yang di ajarkan pada jaringan komputer

Tabel 3. Uji Media

\begin{tabular}{lc}
\hline \multicolumn{1}{c}{ Aspek } & Nilai \\
\hline Bantuan Informasi & 19 \\
\hline Kualitas Tampilan & 50 \\
\hline Kualitas Teknis & 30 \\
\hline Pemanfaatan & 12 \\
\hline Total Skor & 111 \\
\hline Presentase & 96.52 \\
\hline Kategori & Sangat Layak \\
\hline
\end{tabular}

Menampilkan data hasil pengujian validasi media dengan presentase kelayakan sebesar 96.52\% sangat layak yang berisi beberapa menú yang terdapat pada media yang dapat dimanfaatkan oleh pengguna dalam mengoperasikan media pembelajaran

Tabel 4. Uji Pengguna

\begin{tabular}{lcc}
\hline \multicolumn{1}{c}{ Aspek } & Nilai \% & \multicolumn{1}{c}{ Kategori } \\
\hline Bantuan Informasi & 86,7 & Sangat Layak \\
\hline Kualitas isi & 86,48 & Sangat Layak \\
\hline Kualitas Tampilan & 88,5 & Sangat Layak \\
\hline Kualitas Teknis & 84,7 & Sangat Layak \\
\hline Pemanfaatan & 85,3 & Sangat Layak \\
\hline Total & 86,42 & Sangat Layak \\
\hline
\end{tabular}

Pengujian validasi dilakukan dengan uij coba instrument kepada siswa pada matakuliah jaringan komputer dengan materi intranet beberapa aspek yang di nilai oleh pengguna antara lain : kemudahan dalam mendapatkan bantuan informasi, Kualitas isi materi, Kualitas teknis beserta Kualitas tampilan dan pemanfaatan dari beberapa aspek tersebut pengguna memberikan respon dengan presentase $86,42 \%$ dengan kategori Sangat layak.

\section{SIMPULAN}

Pengembangan media pembelajaran interaktif dapat menambah media dalam pembelajaran mata pelajaran komputer dan jaringan pada materi intranet. Media ini bukan haya berupa teks atau video tetapi juga berisi gambar, audio, video, teks, kuis yang lebih interaktif yang bisa lebih menarik dalam proses belajar. Hasil kelayakan aplikasi yang dibuat dengan materi perakitan dan perawatan komputer di mata pelajaran komputer dan jaringan dasar memperoleh hasil "Sangat Layak" dengan skor dari ahli materi sebesar $86,38 \%$, ahli media sebesar $96,52 \%$, dan dari pengguna sebesar $86,42 \%$. Hal ini dapat ditarik kesimpulan bahwa media ini dapat digunakan dalam proses pembelajaran pada jaringan komputer.

\section{DAFTAR RUJUKAN}

Arikunto, Suharsimi. (2013). Prosedur Penelitian (Suatu Pendekatan Praktik), Jakarta: PT Asdi Mahasatya.

Arsyad, A. (2014). Media Pembelajaran . Jakarta: PT. Raja Grafindo Persada.

Azhar, S. (2018). Reliabilitas dan validitas. Yogyakarta: Pustaka Belajar.

Daryanto. (2013). Media Pemebalajran peranan sangat penting dalam mencapai tujuan pembelajaran. Yogyakarta: Gava Media.

Mulyatiningsih, E. (2013). Metode penelitian terapan bidang pendidikan. Bandung: Alfabeta.

Munadi, Y. (2018). Pengembangan media pembelajaran interaktif kompetensi dasar register berbasis inkuiri terbimbing. Jurnal pendidikan teknologi dan kejuruan, 22.

Munir. (2015). Multimedia konsep dan aplikasi dalam pendidikan. Bandung: Alfabeta.

Pujiriyanto. (2012). teknologi untuk pengembangan media dan pembelajaran. Yogyakarta: UNY Press.

Putro, E. (2017). Evaluasi program pembelajaran. Yogyakarta: Pustaka belajar.

Sadiman, A. (2014). Media pendidikan pengertian pengemabangan dan pemanfaatan. Jakarta: PT. Raja Grafindo Persada.

Sanaky, H. (2009). Media Pendidikan. Yogyakarta: Safiria Insania Press. 
Sudjana, N. (2009). Media pengejaran. Bandung: Sinar Baru Algesindo.

Sugiyono. (2015). Metode penelitian pendidikan. Bandung: Alfabeta.

Sugiyono. (2016). Metode penelitian dan pengembangan Research and development. Bandunng: Alfabeta.

Suyitno. (2016). Pengembangan multimedia. Yogyakarta: Graha Ilmu.

Suyitno. (2016). pengembangan mutimedia interaktif pengukuran teknis untuk meningkatkan hasil belajar siswa SMK. Jurnal pendidikan teknologi dan kejuruan, 23.

Wati, R. e. (2016). Ragam media pembelajaran. Jakarta: Kata Pena.

Wibawanto, W. (2016). Desain dan pemrograman multimedia pembelajaran interaktif. Jember: Cerdas Ulet Kreatif. 